This is the final peer-reviewed accepted manuscript of:

O. Shemchuk, D. Braga, F. Grepioni, Alloying barbituric and thiobarbituric acids: From solid solutions to a highly stable keto co-crystal form, Chem. Commun. 2016, 52, $11815-11818$

The final published version is available online at: https://doi.org/10.1039/c6cc06615A

Rights / License:

The terms and conditions for the reuse of this version of the manuscript are specified in the publishing policy. For all terms of use and more information see the publisher's website.

This item was downloaded from IRIS Università di Bologna (https://cris.unibo.it/)

When citing, please refer to the published version. 


\title{
Alloying barbituric and thiobarbituric acids: from solid solutions to a highly stable keto co-crystal form $\dagger$
}

\author{
O. Shemchuk, D. Braga and F. Grepioni*
}

\begin{abstract}
Alloying isomorphous crystals of barbituric acid (BA) and thiobarbituric acid (TBA) yields solid solutions of general formula $\mathrm{BA}_{x} \mathrm{TBA}_{1-x}$ $(x<0.8)$; for $x=0.5$ the stable co-crystal $B_{0.5} T_{B A} A_{0.5}$, isomorphous with the parent keto forms, is observed, which melts at $265^{\circ} \mathrm{C}$, i.e. ca. 10 and $20^{\circ} \mathrm{C}$ higher than the melting points of $B A$ and TBA, respectively. While the $\mathrm{BA}_{x} \mathrm{TBA}_{1-x}$ solid solutions with $x>0.5$ are stable, those with $x<0.5$ convert, with time or temperature, to the $\mathrm{BA}_{0.5} \mathrm{TBA}_{0.5}$ co-crystal.
\end{abstract}

Multicomponent molecular solids are attractive targets in the quest for novel molecular materials with potential applications in various areas, from pharma to agrochemicals, nutraceuticals, high energy materials, pigments, etc. These systems fall within the conceptual framework of molecular crystal engineering, ${ }^{1}$ which provides the conceptual tools to assemble molecular components into crystalline supramolecular networks to achieve the desired properties. ${ }^{2}$ Because of this, and for different reasons, two areas of molecular crystal engineering are being intensely explored: the possible existence of more than one crystal structure for the same molecule, i.e. crystal polymorphism, ${ }^{3}$ and the effect of crystallization of a molecule of interest, for example an active pharmaceutical ingredient (API), with one or more molecules that are solid under ambient conditions, i.e. co-crystals. ${ }^{4}$ More recently, though, solid solutions of organic compounds have experienced a renaissance in view of the possibility of fine tuning or improving solid-state physico-chemical properties. ${ }^{5}$ During the last 15 years we have also contributed to the field with the study of organic and organometallic alloys/solid solutions. $^{6}$

A crystalline organic solid solution is a nonstoichiometric substitutional mixed crystal $^{7}$ resulting from a statistical mixing in a narrow to broad composition range - of quasi isostructural

Dipartimento di Chimica Giacomo Ciamician, Università degli Studi di Bologna, Via Selmi 2, 40126 Bologna, Italy. E-mail: fabrizia.grepioni@unibo.it

$\dagger$ Electronic supplementary information (ESI) available: CIF files, synthesis, structural characterization, powder X-ray diffraction patterns, and DSC traces. CCDC 1498572-1498574. For ESI and crystallographic data in CIF or other electronic format see DOI: $10.1039 / \mathrm{c} 6 \mathrm{cc} 06615 \mathrm{a}$ components forming a single crystalline phase. In the case of metal atoms it is more common to use the term substitutional "alloy", although the term has also been used to describe organic systems. ${ }^{8}$

In a solid solution guest molecules substitute, generally in a random fashion, host molecules in the final crystal structure. According to Kitaigorodsky's basic rule of solubility, "the similarity of the shapes of molecules is a necessary condition of solubility", although a further important condition is that the replacement of the solvent molecules by the solute molecules “does not disturb significantly the molecular packing”, especially when an intermolecular hydrogen bonding network is present in one or both parent compound(s). Isomorphous solids are usually prone to form solid solutions, ${ }^{9}$ but there are notable exceptions. $^{7}$

Provided that the energy gain is sufficient, the mixing of two organic solid components ${ }^{7}$ can result in the formation of a solid solution, or in the formation of a heterophase system showing a eutectic point, or in an ordered crystalline material, i.e. a co-crystal. The possibility of forming a simple physical mixture also needs to be taken into account. ${ }^{7}$

Therefore there is a relationship between co-crystals and solid solutions, since a co-crystal may represent a special point in the mixed-crystal stability domain.

Barbituric acid (BA) and thiobarbituric acid (TBA) are useful compounds for the benchmarking of solid solution preparation, also in view of the intriguing relationship between molecular and crystal structures arising from the keto-enol tautomerism characteristic of these species. In collaboration with others, we have recently shown that, contrary to what is commonly reported, the thermodynamically stable crystal form of BA is not formed by molecules of the keto tautomer but rather by those of the enol tautomer $^{10 a}$ (this result has also recently been confirmed by single crystal X-ray diffraction ${ }^{10 b}$ ). In collaboration with others we have also shown that the most stable crystal form of TBA is a co-crystal formed by both the keto and enol tautomers. ${ }^{11}$ The commercially available forms of both BA and TBA, however, i.e. form II (BARBAC02 ${ }^{12}$ ) and form I (THBARB $\left.{ }^{13}\right)$, respectively, 

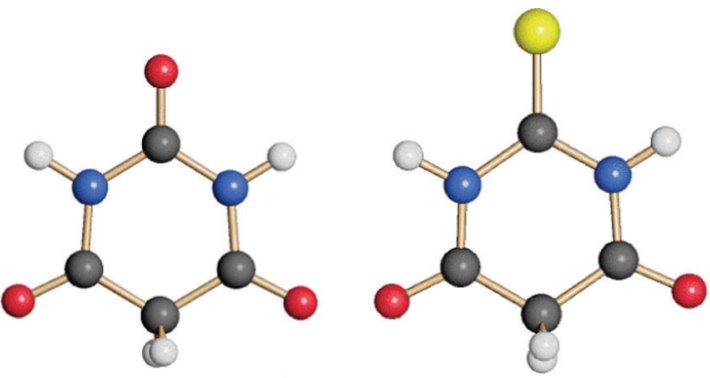

Fig. 1 The BA and TBA keto tautomers present in their isomorphous crystals [commercial forms II (BARBAC02) and I (THBARB), respectively].

contain only the keto tautomer (see Fig. 1) and are isomorphous in the space group $P 2_{1} / c$.

This isomorphicity prompted the following questions: (i) would the difference in size between the two molecules, albeit within isomorphous crystals, permit solid-state mixing? And (ii) if this happens, would the keto tautomeric structure be maintained in the solid solutions or would the enol form prevail?

In this communication we answer these questions and also add a discovery step, because of the identification of a highly stable co-crystal $\mathrm{BA}_{0.5} \mathrm{TBA}_{0.5}$. The two-component $\mathrm{BA}_{x} \mathrm{TBA}_{1-x}$ materials have been prepared and characterized by DSC and powder X-ray diffraction; in the cases of $x \geq 0.5$ single crystal structural characterization was also possible.

All the $\mathrm{BA}_{x} \mathrm{TBA}_{1-x}$ solid solutions were obtained (see the ESI $\dagger$ ) by dissolution of the starting materials, in an appropriate molar ratio, in boiling EtOH; the solution was left to evaporate at room temperature. The $\mathrm{BA}_{0.5} \mathrm{TBA}_{0.5}$ co-crystal was also obtained by nonsolution methods, ${ }^{14}$ i.e. via kneading with $\mathrm{EtOH}$ at room temperature, and by co-melting a physical mixture in a hot-stage microscopy experiment or via a DSC heating cycle of a physical mixture (see below). The structure of the $\mathrm{BA}_{0.5} \mathrm{TBA}_{0.5}$ co-crystal is isomorphous with those of BA form II and TBA form I; it crystallizes in the space group $P 2_{1} / c$, with a cell volume that is between those of the parent components (see Table S1 and Fig. S1, ESI $\dagger$ ), and with two independent molecules, both in the keto form, in the asymmetric unit. The hydrogen bonding pattern observed in BA form II and TBA form I is also maintained in the solid solutions, with two large hydrogen bonded

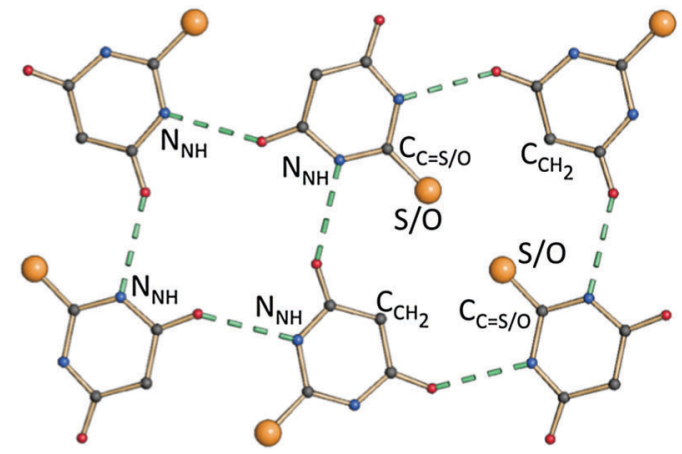

Fig. 2 The hydrogen bonding pattern connecting the keto tautomers observed in $\mathrm{BA}$ form II, in TBA form I and in the $\mathrm{BA}_{x} \mathrm{TBA}_{1-x}$ solid solution.
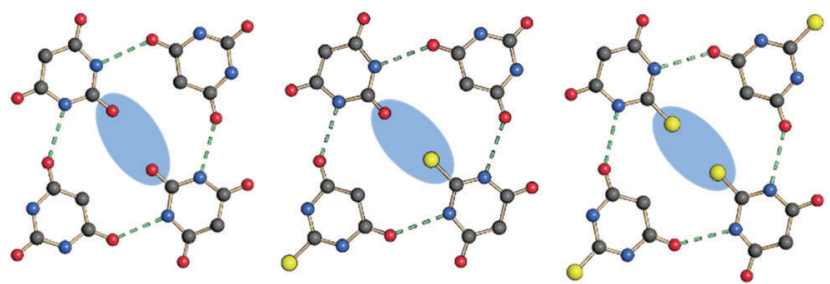

Fig. 3 The $\mathrm{O} \ldots \mathrm{O}, \mathrm{S} \ldots \mathrm{O}$ and $\mathrm{S} \ldots \mathrm{S}$ sites in $\mathrm{BA}$ form II at low temperature (left, $3.32 \AA$ ), in $\mathrm{BA}_{0.5} \mathrm{TBA}_{0.5}$ (middle, 3.05(2) $\AA$ ) and TBA form I (right, $3.13 \AA$ ), respectively. $\mathrm{S} \cdots \mathrm{S}$ contacts are ruled out in $\mathrm{BA}_{0.5} \mathrm{TBA}_{0.5}$, as they would be too short (2.56(1) $\AA$ ).

rings (see Fig. 2) forming 2D parallel planes perpendicular to the crystallographic ac-plane (see Fig. S2, ESI $\dagger$ ).

As expected, there is a $\mathrm{S} / \mathrm{O}$ occupational disorder, with the $\mathrm{S}$ - and O-atom occupancy equal to 0.5 (see the ESI $\dagger$ ). The site occupation, however, is in such a way as to allow acceptable next neighbour S $\cdots \mathrm{O}$ intermolecular contacts of $c a$. 3.05(2) $\AA$, and this is achieved only if vicinal sites (see Fig. 3) in $\mathrm{BA}_{0.5} \mathrm{TBA}_{0.5}$ are not occupied by atoms of the same type: while an $\mathrm{O} \cdots \mathrm{O}$ separation would be only slightly longer than that observed at low temperature in BA form II (ca. 3.54(1) vs. $3.32 \AA$, respectively), a S $\cdots \mathrm{S}$ contact would be exceedingly short, i.e. 2.56(1) ̊ vs. $3.13 \AA$, the value observed in TBA form I.

Fig. 4 shows how the BA and TBA molecules are arranged within the hydrogen bonded layers in BA form II, $\mathrm{BA}_{0.5} \mathrm{TBA}_{0.5}$ and TBA form I.

The effect of substituting sulphur for oxygen, upon passing from BA form II to TBA form I, is represented in Scheme 1: the lozenge, whose vertices are the $\mathrm{C}_{\mathrm{C}}=\mathrm{S} / \mathrm{O}$ and $\mathrm{C}_{\mathrm{CH}_{2}}$ carbon atoms evidenced on the right-hand side of Fig. 2, becomes increasingly more symmetric upon increasing the sulphur content, to allow for both reasonable $\mathrm{S} \cdots \mathrm{S}$ contacts and optimization of intermolecular $\mathrm{N}-\mathrm{H} \cdots \mathrm{O}$ hydrogen bonds. Upon increasing the oxygen content the number of $\mathrm{C}=\mathrm{O}$ groups facing each other (see Fig. 3 and 4), i.e. the percentage of $\mathrm{O} \cdots \mathrm{O}$ contacts, increases and the number of $\mathrm{S} \cdots \mathrm{S}$ decreases, and this is reflected in the cell volume, which decreases accordingly (see the ESI $\dagger$ ).

Diffraction data show evidence of solid phase formation isomorphous with BA and TBA for values of $x$ in the $0.50-0.80$ range (see the ESI $\dagger$ ); for these solid solutions single crystals could be obtained, and their simulated patterns are compared with that of co-crystal $\mathrm{BA}_{0.5} \mathrm{TBA}_{0.5}$. Fig. 5 shows an expanded section of the

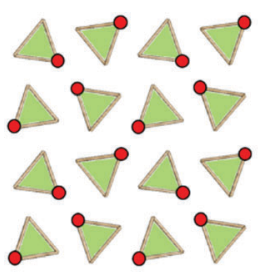

BA
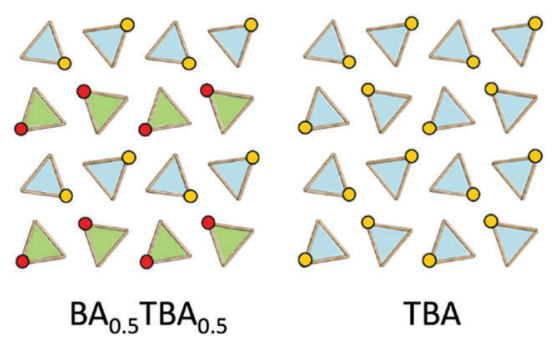

TBA
Fig. 4 Relative disposition of the BA (green triangle) and TBA (light blue triangle) molecules within the hydrogen bonded layers in BA form II, $\mathrm{BA}_{0.5} \mathrm{TBA}_{0.5}$ and TBA form I. 

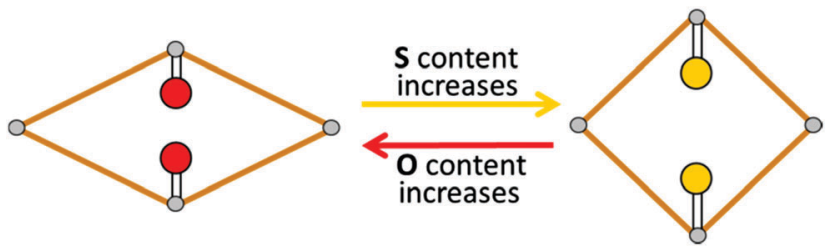

Scheme 1 Progressive symmetrisation (S content increases) or asymmetrisation ( $\mathrm{O}$ content increases) of the lozenge with $\mathrm{C}_{\mathrm{C}}=\mathrm{S} / \mathrm{O}$ and $\mathrm{C}_{\mathrm{CH}_{2}}$ at its vertices, necessary to compensate for the difference in oxygen and sulphur radii, while preserving the intermolecular hydrogen bonding pattern.

XRPD patterns: upon increasing the BA content, a shift towards higher angles of the (202) peak, taken as a representative, is evidenced, due to variation in the unit cell parameters. In the case of excess of TBA, i.e. for $x$ in the 0.2-0.4 range, a similar trend in the opposite direction is present in the experimental powder patterns (see Fig. S2, ESI $\dagger$ ), although the evidence is less clear-cut. Unfortunately, obtaining single crystals for this composition has so far been unsuccessful.

The solvent used for the crystallization plays a crucial role in the formation of solid solutions. If EtOH is used, solid solutions are obtained, while with a more polar solvent, like methanol, from which the enol form of BA can be obtained, ${ }^{10 b}$ the co-crystal $\mathrm{BA}_{0.5} \mathrm{TBA}_{0.5}$ is invariably crystallized, together with an excess of pure acid as such or in its hydrated form (see Fig. S3, ESI $\dagger$ ). Attempts to prepare a tautomeric polymorph of the $\mathrm{BA}_{0.5} \mathrm{TBA}_{0.5}$ co-crystal by crystallization from a hot $\mathrm{CH}_{3} \mathrm{CN}$ solution, or in the solid state by kneading (with a few drops of $\mathrm{CH}_{3} \mathrm{CN}$ ) BA form II with TBA form $\mathrm{IV}^{11}$ i.e. the keto-enol co-crystal form, invariably led to the formation of the same keto $\mathrm{BA}_{0.5} \mathrm{TBA}_{0.5}$ co-crystal (see Fig. S4, ESI $\dagger$ ).

Insights into the co-crystal vs. solid solution behaviour were obtained from DSC measurements (see the ESI $\dagger$ ). Quite unexpectedly, the co-crystal was found to melt at $c a .265{ }^{\circ} \mathrm{C}$ (peak temperature), a value higher than the melting points of

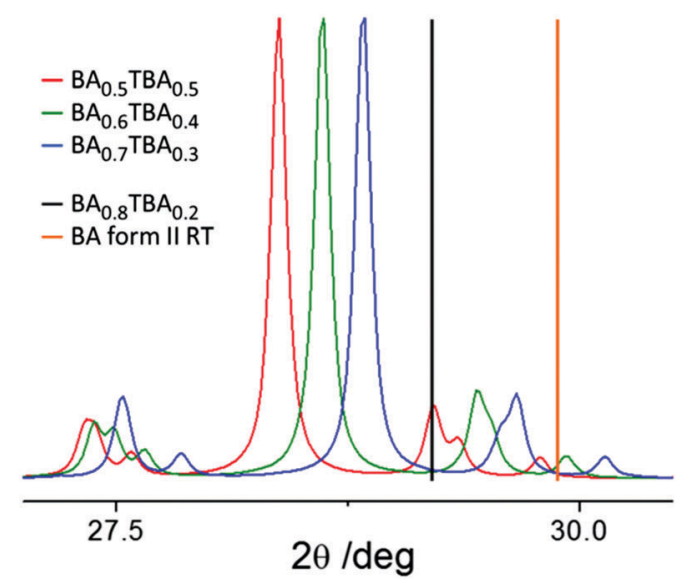

Fig. 5 Calculated XRPD patterns of $\mathrm{BA}_{x} \mathrm{TBA}_{1-x}$ solid solutions with $x \geq 0.5$ : expanded section showing the shift of the (202) peak towards higher angles upon increasing the percentage of BA. The position of the (202) peak is also shown for $\mathrm{BA}_{0.8} \mathrm{TBA}_{0.2}$ (black line, $2 \theta=29.2 \mathrm{deg}$ ) and $\mathrm{BA}$ form II at $\mathrm{RT}^{12 b}$ (orange line, $2 \theta=29.9 \mathrm{deg}$ ), for which single crystal cell parameters are available (see the $\mathrm{ESI} \dagger$ ).

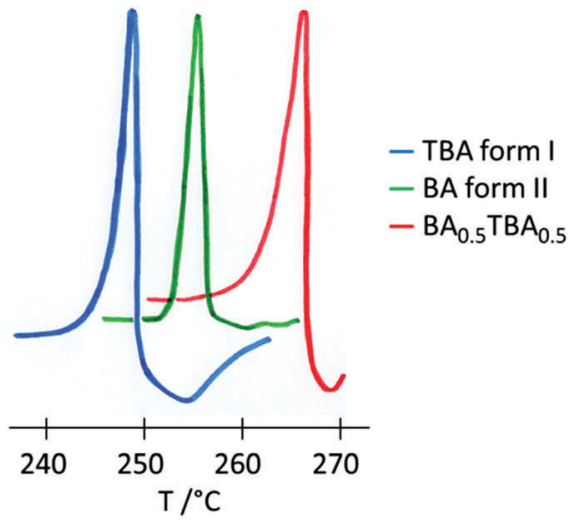

Fig. 6 Comparison of DSC traces for TBA form I, BA form II and BA $\mathrm{B}_{0.5} \mathrm{TBA}_{0.5}$, showing the higher thermal stability of the co-crystal with respect to the parent compounds.

both barbituric $\left(255^{\circ} \mathrm{C}\right)$ and thiobarbituric acid $\left(248{ }^{\circ} \mathrm{C}\right)$ (peak temperatures) (see Fig. 6). Thus, the co-crystal is more thermally stable compared to the starting materials. This phenomenon is rather unusual, as in the large majority of cases the melting points of co-crystals are either between or lower than those of the parent components. ${ }^{15} \mathrm{~A}$ recent review by Perlovich ${ }^{15 c}$ on organic co-crystals of pharmaceutical interest indicates that the melting points of co-crystals are, on average, higher, between, or lower than those of the corresponding pure components in ca. $16 \%, 55 \%$ and $29 \%$ of the cases, respectively.

DSC traces of the $\mathrm{BA}_{x} \mathrm{TBA}_{1-x}$ solid solutions with $x<0.5$, i.e. with an excess of TBA, obtained by crystallization from solution show that, upon heating, the crystalline materials are unstable with respect to "demixing": melting of BA and TBA is therefore observed, followed by recrystallization to the $\mathrm{BA}_{0.5} \mathrm{TBA}_{0.5}$ co-crystal (see the ESI $\dagger$ ). It might also be that the polycrystalline powder is formed by a mixture of phases; however, the relevant issue is that, while both BA and TBA decompose upon melting, melting of the solid solutions, or even melting of one acid in the presence of the other, enhances the thermal stability of BA and TBA by $c a$. 10 and $20{ }^{\circ} \mathrm{C}$, respectively.

The $\mathrm{BA}_{0.5} \mathrm{TBA}_{0.5}$ co-crystal was obtained also by melting an equimolar physical mixture of BA and TBA in a hot stage microscopy experiment (see the ESI $\dagger$ ); Fig. 7 shows single crystals of $\mathrm{BA}_{0.5} \mathrm{TBA}_{0.5}$ (formed upon melting of the starting materials) that are still stable at $262{ }^{\circ} \mathrm{C}$. This observation was confirmed via DSC measurements carried out on BA-TBA physical mixtures (see the ESI $\dagger$ ).

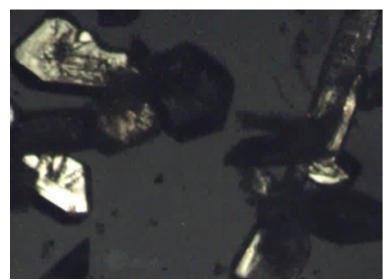

Fig. 7 Hot stage microscopy: image (100x, taken with an Olympus optical microscope) of $\mathrm{BA}_{0.5} \mathrm{TBA}_{0.5} \mathrm{co}$-crystals at $262^{\circ} \mathrm{C}$. The crystals were obtained after co-melting a 50:50 physical mixture of BA and TBA. 
In the course of these studies we also noticed that the solid solutions $\mathrm{BA}_{x} \mathrm{TBA}_{1-x}$ with $x<0.5$, kept under ambient conditions, show a tendency to transform with time into the $\mathrm{BA}_{0.5} \mathrm{TBA}_{0.5}$ co-crystal. New XRPD measurements of $\mathrm{BA}_{x} \mathrm{TBA}_{1-x}$ samples approximately one month after they had been prepared and analysed for the first time showed intriguing results: while the patterns of $\mathrm{BA}_{0.6} \mathrm{TBA}_{0.4}$ and $\mathrm{BA}_{0.7} \mathrm{TBA}_{0.3}$ remained unchanged, those of $\mathrm{BA}_{0.4} \mathrm{TBA}_{0.6}$ and $\mathrm{BA}_{0.3} \mathrm{TBA}_{0.7}$, i.e. with an excess of thiobarbituric acid, had decomposed to the $\mathrm{BA}_{0.5} \mathrm{TBA}_{0.5}$ co-crystal and TBA (see Fig. S5, ESI $\dagger$ ). The solid solutions with an excess of BA were re-measured after 3 months of standing in air under ambient conditions, but they still remained unchanged (see Fig. S6, ESI $\dagger$ ). Thus, it is possible to conclude that solid solutions with an excess of BA are more stable than those with an excess of TBA when kept under ambient conditions. The co-crystal $\mathrm{BA}_{0.5} \mathrm{TBA}_{0.5}$ also represents the thermodynamic evolution with time or upon heating of $\mathrm{BA}_{x} \mathrm{TBA}_{1-x}$ physical mixtures or solid solutions.

In summary the BA-TBA solid system represents an intriguing situation for which the equimolar mixture generates a packing that is observed with the co-crystal $\mathrm{BA}_{0.5} \mathrm{TBA}_{0.5}$ - which is more favoured with respect to the parent homo-molecular crystalline materials. All these mixed crystals are isomorphous with those of the parent components. This is, to the best of the authors' knowledge, the first observation of two isomorphous molecular crystals forming metastable solid solutions, depending on the composition, as well as a stable co-crystal.

This work was supported by the University of Bologna. The authors would like to acknowledge Dr Katia Rubini for her assistance with the DSC measurements.

\section{Notes and references}

1 (a) G. R. Desiraju, Crystal engineering: the design of organic solids, Elsevier, Amsterdam, 1989; (b) G. R. Desiraju, Angew. Chem., Int. Ed., 1995, 34, 2311-2327; (c) G. R. Desiraju, Angew. Chem., Int. Ed., 2007, 46, 8342-8356.

2 (a) C. B. Aakeröy, N. R. Champness and C. Janiak, CrystEngComm, 2010, 12, 22-43; (b) D. Braga, L. Brammer and N. R. Champness, CrystEngComm, 2005, 7, 1-19; (c) D. Braga, Chem. Commun., 2003, 2751-2755; (d) K. Biradha and R. Santra, Chem. Soc. Rev., 2013, 42, 950-967; (e) Making Crystals by Design - Methods, Techniques, Applications, ed. D. Braga and F. Grepioni, Wiley-VCH, 2006.

3 (a) D.-K. Bučar, R. W. Lancaster and J. Bernstein, Angew. Chem., 2015, 54, 6972-6993; (b) A. J. Cruz-Cabeza and J. Bernstein, Chem.
Rev., 2014, 114, 2170-2191; (c) A. Cruz-Cabeza, S. Reutzel-Edens and J. Bernstein, Chem. Soc. Rev., 2015, 44, 8619-8635.

4 (a) O. Almarsson and M. J. Zaworotko, Chem. Commun., 2004, 1889; (b) N. K. Duggirala, M. L. Perry, O. Almarsson and M. J. Zaworotko, Chem. Commun., 2016, 52, 640-655; (c) J. W. Steed, Trends Pharmacol. Sci., 2013, 34, 3; (d) H. G. Brittain, Cryst. Growth Des., 2012, 12, 5823-5832; (e) M. L. Cheney, D. R. Weyna, N. Shan, M. Hanna, L. Wojtas and M. J. Zaworotko, J. Pharm. Sci., 2011, 100, 2172-2181; $(f)$ D. J. Good and N. Rodríguez-Hornedo, Cryst. Growth Des., 2009, 9, 2252-2264; $(g)$ J. Wouters and L. Quéré, Pharmaceutical salts and co-crystals, Royal Society of Chemistry, 2011; $(h)$ S. Cherukuvada and A. Nangia, CrystEngComm, 2014, 50, 906-923.

5 (a) M. Lusi, I. J. Vitorica-yrezabal and M. J. Zaworotko, Cryst. Growth Des., 2015, 15, 4098-4103; (b) E. Schur, E. Nauha, M. Lusi and J. Bernstein, Chem. - Eur. J., 2015, 21, 1735; (c) K. Suresh, M. K. C. Mannava and A. Nangia, CrystEngComm, 2016, 52, 4223-4246.

6 M. Polito, E. D’Oria, L. Maini, P. G. Karamertzanis, F. Grepioni, D. Braga and S. L. Price, CrystEngComm, 2008, 10, 1848-1854; D. Braga, F. Grepioni, L. Maini, M. Polito, K. Rubini, M. R. Chierotti and R. Gobetto, Chem. - Eur. J., 2009, 15, 1508-1515; D. Braga, G. Cojazzi, D. Paolucci and F. Grepioni, Chem. Commun., 2001, 803-804.

7 A. I. Kitaigorodsky, Mixed crystals, Springer Science \& Business Media, 2012, vol. 33.

8 (a) S. P. Thomas, R. Sathishkumar and T. N. G. Row, Chem. Commun., 2015, 51, 14255-14258; (b) T. Friščić, A. V. Trask, W. Jones and W. D. S. Motherwell, Angew. Chem., Int. Ed., 2006, 45, 7546-7550; (c) A. A. Bredikhin, Z. A. Bredikhina, D. V. Zakharychev, A. T. Gubaidullin and R. R. Fayzullin, CrystEngComm, 2012, 14, 648-655; (d) K. D. Prasad, S. Cherukuvada, L. D. Stephen and T. N. Guru Row, CrystEngComm, 2014, 16, 9930-9938; (e) S. Cherukuvada and A. Nangia, Chem. Commun., 2014, 58, 906-923.

9 International Union of Crystallography. Isomorphous crystals http:// reference.iucr.org/dictionary/Isomorphous_crystals.

10 (a) M. U. Schmidt, J. Brüning, J. Glinnemann, M. W. Hützler, P. Mörschel, S. N. Ivashevskaya, J. van de Streek, D. Braga, L. Maini, M. R. Chierotti and R. Gobetto, Angew. Chem., Int. Ed., 2011, 50, 7924-7926; (b) M. G. Marshall, V. Lopez-Diaz and B. S. Hudson, Angew. Chem., Int. Ed., 2016, 55, 1309-1312.

11 M. R. Chierotti, L. Ferrero, N. Garino, R. Gobetto, L. Pellegrino, D. Braga, F. Grepioni and L. Maini, Chem. - Eur. J., 2010, 16, 4347-4358.

12 (a) T. C Lewis, D. A. Tocher and S. L. Price, Cryst. Growth Des., 2004, 4, 979-987; for room temperature cell parameters see: $(b)$ M. V. Roux, M. Temprado, R. Notario, C. Foces-Foces, V. N. Emel'yanenko and S. P. Verevkin, J. Phys. Chem. A, 2008, 112, 7455-7465.

13 M.-R. Calas and J. Martinez, C. R. Seances Acad. Sci., Ser. C, 1967, 265, 631-634.

14 (a) L. J. Stuart, C. Adams, C. Bolm, D. Braga, P. Collier, T. Friščić, F. Grepioni, K. Harris, G. Hyett, W. Jones, A. Krebs, J. Mack, L. Maini, A. G. Orpen, I. Parkin, W. Shearouse, J. W. Steed and D. C. Waddell, Chem. Soc. Rev., 2012, 41, 413-447; (b) D. Braga, L. Maini and F. Grepioni, Chem. Soc. Rev., 2013, 42, 7638-7648.

15 (a) M. K. Stanton and A. Bak, Cryst. Growth Des., 2008, 8, 3856-3862; (b) N. Schultheiss and A. Newman, Cryst. Growth Des., 2009, 9, 2950-2967; (c) G. L. Perlovich, CrystEngComm, 2015, 7, 7019-7028. 